\title{
Substitutes of structural and non-structural autologous bone grafts in hindfoot arthrodeses and osteotomies: a systematic review
}

\author{
Marc Andreas Müller ${ }^{1 *}$, Alexander Frank1', Matthias Briel2,3, Victor Valderrabano ${ }^{1}$, Patrick Vavken 1,4,
} Vahid Entezari ${ }^{4}$ and Arne Mehrkens ${ }^{1}$

\begin{abstract}
Background: Structural and non-structural substitutes of autologous bone grafts are frequently used in hindfoot arthrodeses and osteotomies. However, their efficacy is unclear.

The primary goal of this systematic review was to compare autologous bone grafts with structural and non-structural substitutes regarding the odds of union in hindfoot arthrodeses and osteotomies.

Methods: The Medline and EMBASE and Cochrane databases were searched for relevant randomized and non-randomized prospective studies as well as retrospective comparative chart reviews.

Results: 10 studies which comprised 928 hindfoot arthrodeses and osteotomies met the inclusion criteria for this systematic review. The quality of the retrieved studies was low due to small samples sizes and confounding variables. The pooled random effect odds for union were 12.8 (95\% Cl 12.7 to 12.9) for structural allografts, 5.7 (95\% Cl 5.5 to 6.0) for cortical autologous grafts, $7.3(95 \% \mathrm{Cl} 6.0$ to 8.6) for cancellous allografts and 6.0 (95\% Cl 5.7 to 6.4) for cancellous autologous grafts. In individual studies, the odds of union in hindfoot arthrodeses achieved with cancellous autologous grafts was similar to those achieved with demineralised bone matrix or platelet derived growth factor augmented ceramic granules.

Conclusion: Our results suggest an equivalent incorporation of structural allografts as compared to autologous grafts in hindfoot arthrodeses and osteotomies. There is a need for prospective randomized trials to further clarify the role of substitutes of autologous bone grafts in hindfoot surgery.
\end{abstract}

\section{Background}

Hindfoot arthrodeses and osteotomies are performed to treat various pathologies such as posterior tibial tendon insufficiency [1-3], hindfoot osteoarthritis [4-6] and deformities related to posttraumatic conditions $[7,8]$ and neuromuscular disease $[9,10]$. In these procedures, structural (cortical) autologous bone grafts and substitutes are used when an open wedge osteotomy or an interposition arthrodesis is performed to provide mechanical support in the resulting bone gap. On the other hand, non-structural (cancellous) bone grafts and substitutes are utilized for in situ arthrodesis with the intention to promote bone healing.

\footnotetext{
* Correspondence: muelleram@uhbs.ch

'Orthopedic Department University Hospital Basel, Spitalstrasse 21, Basel 4031, Switzerland

Full list of author information is available at the end of the article
}

The hindfoot is a challenging environment for bone healing due to mechanical loading, restricted blood supply and thin soft tissue coverage. Non-unions are observed in up to $14 \%$ [11-14] of patients undergoing hindfoot fusions and osteotomies and even more frequently in patients with impaired bone healing, such as diabetics and smokers $[4,15,16]$. Implanted structural bone grafts may also show collapse under load with consecutive loss of deformity correction [17]. Both, nonunion and graft collapse may lead to unsatisfactory outcomes $[12,18]$. Therefore, the selection of an appropriate bone graft able to withstand these challenges is important in hindfoot arthrodeses and osteotomies.

From a biological standpoint autologous grafts are an excellent choice. They incorporate quickly due to favourable osteoconductivity [19-21] and osteoinductivity [22] as well as potential osteogenicity $[20,23]$. 
Moreover, they display remarkable biomechanical resistance [24]. However, the use of autologous grafts is limited by associated donor site morbidity [25], increased surgery time and finite availability [26-28]. These limitations incline surgeons to use substitutes for autologous bone grafts. Allografts are commonly the first option with similar osteoconductivity and osteoinductivity as compared to autologous grafts [29], but they carry the risk of transmitting infectious diseases [30] and may incite an immunological response [31,32] leading to impaired graft incorporation $[33,34]$ and secondary graft collapse [35]. Further processing of allografts using freeze drying techniques and treating the graft with hypotonic solutions, acetone, ethylenoxide or gamma irradiation can eliminate cellular and viral particles and thus can lower the risk of infectious disease transmission [36-38]. These acellular allografts preserve their osteoconductive properties but studies showed that their mechanical strength and osteointegration may be affected by this process [39].

Alternatively, allografts can be decalcified to extract demineralized bone matrix (DBM) which is known to have osteoinductive and partly osteoconductive properties [40]. However, the osteoinductivity of DBM depends on multiple factors including the manufacturing process $[41,42]$ and the donor [43]. More consistent characteristics may be expected from synthetic substitutes of autologous grafts. Current market options range from very brittle ceramics (made from hydroxapatite [HA] or tricacliumphosphate $[\mathrm{TCP}]$ ) that have favourable osteoconductive properties [44] to more resistant osteoconductive metals such as tantalum [45] as well as costly recombinants of bone morphogenetic proteins (BMPs) [46] and platelet derived growth factors (PDGFs) [47].

Nonetheless, the choice between autologous grafts and different substitutes should not only be based on biologic and biomechanical considerations, but also on the best evidence available in the literature. Thus, the primary goal of this systematic review was to assess the efficacy of autologous bone grafts and their structural and non-structural substitutes to achieve union in hindfoot arthrodeses and osteotomies. As a secondary goal, we aimed to compare the resistance of structural grafts to collapse in these hindfoot procedures.

\section{Methods}

\section{Search strategy}

We conducted an electronic search of Medline, the Cochrane Library, and EMBASE from inception of each database to December 2011 for randomized and nonrandomized, controlled studies on the use of structural and non-structural autologous bone grafts and substitutes in hindfoot osteotomies and arthrodeses. We used "bone transplantation", "allograft", "xenograft", "synthetic bone graft", "beta tricalcium phosphate","hydroxyapatite", "bone morphogenetic protein", "demineralized bone matrix", "foot" as terms or medical subject headings. There were no restrictions with respect to language or date of publication.

Studies eligible for this systematic review had to compare cortical or cancellous autologous bone grafts with any structural or non-structural substitute in patients undergoing subtalar, talonavicular, triple arthrodesis or lateral column lengthening. Only prospective or retrospective, controlled trials with a minimum sample size of 20 patients were eligible for inclusion. All titles and abstracts identified by our search were reviewed by two orthopedic surgeons independently (AF, AMM). If either reviewer deemed an abstract potentially eligible, the full text of that article was obtained and assessed for eligibility by both reviewers. Disagreement was resolved by discussion or consultation with the senior author.

Two reviewers independently extracted patient demographics, operative data, and outcome data from each article. The primary outcome data comprised of rate of union. Secondary outcome data referred to the occurrence of graft collapse either defined as an obvious disintegration of the graft or measured indirectly by a loss of hind- and/or midfoot alignment. In addition, time-tounion was recorded.

\section{Quality assessment of retrieved studies}

The methodological quality of included studies was independently assessed by two reviewers (AMM, AM). Randomized controlled trials were assessed based on concealment of treatment allocation, blinding of outcome assessors, completeness of follow-up, and the attainment of sufficient power to detect significant differences. The Newcastle-Ottawa Quality assessment scale [48] was used for the quality assessment of nonrandomized studies. In this context, the included studies were evaluated according to three main categories, i.e. "selection", "comparability" and "outcome". Each of these categories comprised several evaluation criteria: Within the category "selection", each study was assessed regarding the representativeness of the (1) exposed and the (2) unexposed study cohort and (3) the ascertainment of exposure to the surgical procedure and graft of interest. It was also verified whether (4) the outcome of interest was absent at the beginning of the study. Within the category "comparability", it was assessed if the study controlled for confounding variables. Within the category "outcome", each study was tested for (1) blinded or record linked outcome assessment and (2) completeness of follow-up (i.e. a documented follow-rate $\geq 80 \%$ ). It was also assessed if (3) the follow-up time was long enough to detect the outcome of interest. 
As a final summary, stars were allotted to each of the three main categories with each star representing a fulfilled evaluation criterion. A maximum of two stars could be allotted to the category "comparability".

\section{Statistical analyses}

Data for the primary endpoint rate of union could be gathered from all but one included study. Using these data, the odds for union were calculated for structural and non-structural autologous grafts and allografts, independently. For data synthesis, odds were pooled using inverse variance weights in a fixed effects model, and assessed for mathematical between-study heterogeneity using Q statistic. The cut-off was set at a p-value of 0.1 to account for loss of power due to small sample sizes. In case of significant mathematical heterogeneity, the DerSimonian-Laird random effects model [49] was used. This method allows for between-study heterogeneity assuming that the individual study results are different, but normally distributed around a common, pooled effect. We used Egger's regression [50] to test for publication bias.

Since data were collected by type of graft and not by study, the odds rather than the odds ratio are given. All results are given as odds with the 95\% confidence interval (CI). All calculations were done with intercooled STATA 12 (StataCorp LP, College Station, Tx).

\section{Results}

\section{Literature search}

Our online search produced 403 articles in total. After exclusion of duplicates and studies without a control group, 10 studies met our eligibility criteria (Figure 1). Among the ten included studies, seven compared structural autologous bone grafts with substitutes (Table 1). One randomized controlled trial [51] and two retrospective chart reviews $[52,53]$ compared structural allografts with autologous grafts in Evan's osteotomies of the calcaneus. Another three retrospective chart reviews $[17,54,55]$ compared structural allografts with autologous grafts in mixed patient populations that comprised both hindfoot arthrodeses and osteotomies. A subgroup analysis in a retrospective chart review [4] compared structural allografts with autologous grafts in isolated hindfoot arthrodeses.

Four studies on non-stru bone grafts met our inclusion criteria (Table 2) which all included subjects undergoing hindfoot fusions. There was one randomized controlled trial comparing recombinant PDGF augmented ceramic granules with cancellous autologous grafts [56]. In a prospective controlled study [57], DBM was compared with cancellous autologous grafts. The remaining two retrospective chart reviews $[4,58]$ compared cancellous allografts and no graft application with cancellous autologous grafts.

In nine [4,51-58] of the ten included studies rate of union was used as an outcome measure to compare autologous grafts with structural or non-structural substitutes. In all of these nine studies union was defined on the basis of plain radiography or conventional tomography as a bridging trabeculation across the osteotomy gap or arthrodeses site. Two studies [51,57] used absence of pain at the surgical site as an additional criterion for union. In only one study [56] healing was additionally assessed using computed tomography (CT) with union defined as a continuity of the trabecular lines within $50 \%$ of the (joint) space to be bridged.

In four $[17,51,53,54]$ of the ten included studies graft collapse was used as primary or secondary outcome measure. All of these studies compared structural allografts
403 Articles identified and screened for retrieval
383 Abstracts failed to meet inclusion criteria (No comparative study, no intervention of interest)

20 Potentially relevant articles retrieved for full-text review

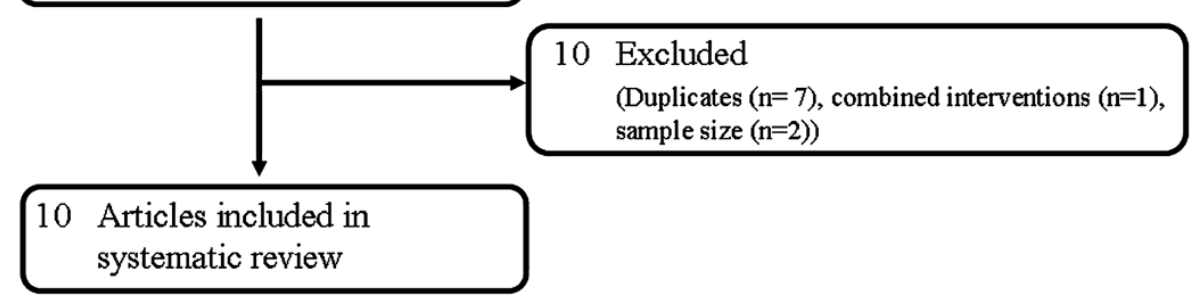

Figure 1 Study flow diagram. 
\begin{tabular}{l} 
Table 1 Studies comparing structural autologous bone grafts with substitutes in hindfoot arthrodeses and osteotomies \\
\hline Ref. $\quad$ Methodology
\end{tabular}

Quality

$\begin{array}{ll}\text { Dolan et al. [51] } & \text { Randomized controlled trial } \\ & 18 \text { freeze-dried structural allografts vs. } 15 \text { cortical autologus grafts in } 31 \text { adults }\end{array}$ undergoing Evan's OTs. FU: 8 and 12 weeks

Templin et al. [52] Retrospective comparative chart review (1994-2003)

30 freeze-dried structural allografts vs 5 structural autologous grafts in 35 children undergoing Evan's OTs. Mean FU 3.6 years (range 6-12 years)

Kwak et al. [53] Retrospective comparative chart review (2000-2005)

118 acellular allografts $\left(\right.$ Tutoplast ${ }^{\circledR}$ ) vs. 10 structural autologous grafts in 79 children undergoing Evan's OTs. Mean FU 15 months (range 13-21months)

\section{Structural allografts versus cortical autologous grafts in hindfoot $A D s$}

Easley et al. [4] Subgroup comparison in a retrospective chart review (1988-1995)

Allografts: $2 / 5(40 \%)$

5 structural allografts vs. 29 structural autologous grafts in isolated subtalar ADs. Mean Autologous grafts: 24/29 (83\%)

FU 51 months (range 24-130 months)

\section{Rate of union}

\section{Rate of union at 8 weeks}

Rate of union at 12 weeks

grafts

graft collapse in both groups

Allografts: $27 / 30(90 \%)$

gous grafts: $4 / 5(80 \%)$

Talo- $1^{\text {st }}$ metatarsal, talo-calcanea

and calcaneal pitch angle at final FU

$\mathrm{P}=$ n.s.

\section{Time to union}

Autologous grafts: 16 weeks (10-30

weeks)

$\mathrm{P}=\mathrm{n} . \mathrm{s}$.
No concealed allocation No blinded outcome assessment 100\% FU Underpowered study

Comparability:

Outcome: *

Selection: ***

Comparability:

Outcome: *

Selection: ***

Comparability:

Outcome: *

Structural allografts versus cortical autologous grafts in miscellaneous procedures (hindfoot ADs/OTs)

Grier et al. [54] Retrospective comparative chart review (1996-2006)

Rate of union

Selection: **

Allografts + PRP: 29/31 (94\%)

Comparability:

31 structural freeze-dried allografts + PRP vs. 20 structural autologous grafts in 18 adult Autologous grafts: 14/20 (70\%)

Outcome: *

Evan's OTs and 33 adult CC ADs. Mean FU: 20 months (range 3-72 months) $\quad P=0.045$

Improvement of the talo- $1^{\text {st }}$

metatarsal and calcaneal pitch angle

No significant difference between the

two graft types 
Table 1 Studies comparing structural autologous bone grafts with substitutes in hindfoot arthrodeses and osteotomies (Continued)

\begin{tabular}{|c|c|c|c|}
\hline \multirow[t]{9}{*}{ Danko et al. [17] } & \multirow[t]{2}{*}{ Retrospective comparative chart review (1990-1992) } & Graft collapse & Selection: *** \\
\hline & & Evan's OT: & Comparability: \\
\hline & \multirow{7}{*}{$\begin{array}{l}7 \text { structural allografts vs } 33 \text { structural autologous grafts in } 69 \text { pediatric Evan's OTs and } \\
61 \text { pediatric CC ADs. Mean FU } 2.5 \text { years (range 0.6-7.8 years) }\end{array}$} & Allografts: 0/39 & \multirow[t]{7}{*}{ Outcome: $* * *$} \\
\hline & & Autologous grafts $0 / 30$ & \\
\hline & & $P=?$ & \\
\hline & & CC ADs: & \\
\hline & & Allografts: $17 / 58(29 \%)$ & \\
\hline & & Autologous grafts: $0 / 3(0 \%)$ & \\
\hline & & $P=?$ & \\
\hline \multirow[t]{9}{*}{ Mahan et al. [55] } & \multirow[t]{2}{*}{ Retrospective comparative chart review (1977-1990) } & Rate of union & Selection: ** \\
\hline & & Allografts: 198/215 & Comparability: \\
\hline & \multirow{7}{*}{$\begin{array}{l}215 \text { freeze dried allografts vs } 85 \text { autologous grafts in } 153 \text { OTs, } 55 \text { ADs, } 82 \text { other } \\
\text { procedures. Minimum FU } 6 \text { weeks }\end{array}$} & $(92 \%)$ & \multirow[t]{7}{*}{ Outcome: * } \\
\hline & & Autologous grafts: 78 /85 (92\%), & \\
\hline & & $\mathrm{P}=\mathrm{n} . \mathrm{s}$. & \\
\hline & & Rate of delayed union & \\
\hline & & Allografts: 8/215 (4\%) & \\
\hline & & Autologous grafts 2/85 (2\%) & \\
\hline & & $\mathrm{P}=\mathrm{n} . \mathrm{s}$. & \\
\hline
\end{tabular}


Table 2 Studies comparing non-structural autologous bone grafts with substitutes in hindfoot arthrodeses and osteotomies

Quality

Cancellous allografts versus cancellous autologous grafts in hindfoot ADs

McGarvey et al. [58] Retrospective comparative chart review (1990-1992)_ Rate of union Selection: ***

Allografts: $21 / 24(88 \%) \quad$ Comparability:

24 acellular allograft chips vs 17 cancellous autologous grafts in 37 subtalar, double Autologous grafts: 16/17 Outcome:*

and triple ADs. FU: Minimum 18 months (94\%)

$\mathrm{P}=$ ?

\section{Time-to- union}

Triple/Double/Subtalar AD

Allografts: 4.0/4.0/4.1 months

Autologous grafts 3.0/3.2/3.6

months

$P=n . s$

Easley et al. [4] Subgroup comparison in a retrospective chart review (1988-1995)

\section{Rate of union}

Selection: **

Allografts: $14 / 17(82 \%) \quad$ Comparability:

17 cancellous allograft vs. 94 cancellous autologous grafts in subtalar ADs. Mean FU Autologous grafts: 80/94 Outcome:* 51 months(range: 24-130 months)

$(85 \%)$

$\mathrm{P}=$ n. $\mathrm{s}$.

Time -to- union

Allografts: 13 weeks

(10-24 weeks)

Autologous grafts: 11 weeks

(8-20 weeks)

$\mathrm{P}=\mathrm{n} . \mathrm{s}$

$D B M$ versus cancellous autologous grafts in hindfoot $A D s$

Michelson et al. Prospective comparative study (1990-1993)

37 DBM vs.18 cancellous autologous grafts in 11 subtalar AD's, and 44 triple AD's

FU: Until complete healing
Rate of union

DBM: 36/37 (97\%)

Autologous grafts: 16/18

(89\%)

$\mathrm{P}=\mathrm{n} . \mathrm{s}$.

Time -to-union

DBM: 3.0 - 3.4 months

Autologous grafts 2.7-3.7

months

$\mathrm{P}=\mathrm{n} . \mathrm{s}$
Selection: ***

Comparability:

Outcome:*** 
Table 2 Studies comparing non-structural autologous bone grafts with substitutes in hindfoot arthrodeses and osteotomies (Continued)

\section{No graft versus cancellous autologous grafts in hindfoot ADs}

Easley et al. [4] Subgroup comparison in a retrospective chart review (1988-1995)

39 "no graft" vs 94 cancellous autologous grafts in isolated subtalar ADs. Mean FU 54 months (range: $24-130$ months)

\section{Rate of union}

No graft: 34/39 (87\%)

$(85 \%)$

Synthetic bone grafts versus cancellous autologous grafts in hindfoot $A D s$

DiGiovanni et al.

[56]

\section{Randomized controlled trial (2006/7)}

14 PDGF augmented B-TCP (Augment ${ }^{\circledR}$ ) vs 6 cancellous autologous grafts in 20 adult subtalar, triple, ankle ADs. FU:6, 12 and 36 weeks
Rate of $X$ ray based union at 6-12-36 weeks:

No concealed allocation Blinded outcome assessment 8093\% follow-up Underpowered study
Autologous grafts: 80/94

$\mathrm{P}=\mathrm{n} . \mathrm{s}$.

Time-to-union

No graft: 11w (8-24)

Autologous grafts: 11 weeks

(8-20 weeks)

$\mathrm{P}=\mathrm{n} . \mathrm{s}$

Selection: *

Comparability:

Outcome:*

PDGF/B-TCP:

0/11(0\%)-5/12(42\%)-10/13

Autologous grafts:

0/4 (0\%)-1/3 (33\%)-3/5 (60\%)

$\mathrm{P}=$ ?

Rate of $\mathrm{CT}$ based union at

6-12 weeks

PDGF/B-TCP:

5/13 (38\%)-9/13\% (69\%)

Autologous grafts:

2/5 (40\%)- 3/5 (60\%)

$\mathrm{P}=$ ? 
with autologous grafts in pediatric $[17,53]$ or adult $[51,54]$ lateral column lengthening procedures. Graft collapse was defined on plain radiographs either directly as obvious graft disintegration $[17,51]$ or indirectly based on the associated change of the talo-first metatarsal, talo-calcaneal and calcaneal pitch angle [53,54].

The quality of retrieved studies is summarized in Table 1 and 2. In brief, all studies had small sample sizes at least in one group and thus limited capacity to detect significant differences. In both randomized controlled trials, patient allocation was not concealed and only in the trial by DiGiovanni et al. [56] outcomes were assessed by blinded observers. All non-randomized trial did not control for confounding factors.

Rate of union: structural autologous grafts and allografts Data could be abstracted for 154 implanted structural autologous grafts. The pooled, fixed effects odds of union across all studies for structural autologous grafts was 6.5 (95\% CI 6.0 to 7.0), but showed significant heterogeneity $(\mathrm{p}<0.001)$. Using the DerSimonian-Laird random effects, we calculated the pooled odds of union for autologous grafts to be 5.7 (95\% CI 5.5 to 6.0), which is significantly different from no effect (or odds of 1 ) at a p-value of less than 0.001 . There was no evidence for publication bias $(\mathrm{p}=0.678)$.

For structural allografts, we could collect data on 299 cases. The pooled, fixed effects odds for union were 14.5 ( $95 \%$ CI 14.0 to 14.0 ), but again with significant heterogeneity $(\mathrm{p}<0.001)$. The random effects odds were 12.8 ( $95 \%$ CI 12.7 to 12.9 ), which is significantly different from no effect (or odds of 1 ) at a p-value of less than 0.001 . There was some evidence for publication bias $(\mathrm{p}=0.037)$, suggesting overestimated odds.

The direct comparison of structural autologous grafts and allografts show that the $95 \%$ confidence intervals for union do not overlap, which is indicative of a significant difference.

\section{Rate of union: non-structural autologous grafts and allografts}

In order to quantitatively assess the rate of union for nonstructural autologous grafts, data were abstracted from 228 hindfoot fusions. The pooled fixed odds for union were 6.0 (95\% CI 5.7 to 6.4). Again, there was significant heterogeneity $(\mathrm{p}<0.001)$. The random effects odds were 7.3 (95\% CI 6.0 to 8.6), again significantly different from no effect (or odds of 1 ) with a p-value of less than 0.001 . There was no evidence for publication bias $(\mathrm{p}=0.291)$.

For non-structural allografts, data from only 41 hindfoot fusions from two studies $[4,58]$ could be included into analysis. The pooled fixed odds for union were 5.9 (95\% CI 5.0 to 6.7 ) with again significant heterogeneity $(\mathrm{p}=0.016)$. The random effect odds for union with nonstructural allografts were 5.8 (95\% CI 4.4-7.3).

\section{Rate of union: other non-structural grafts}

For the remaining non-structural grafts data could only be obtained a single study. For these graft types odds for union were calculated based on the individual study results. The odds of union were 6.8 (95\% CI 5.9 to 7.7 ) for patients receiving no graft, 8.0 (95\% CI 6.5 to 9.5) for patients receiving DBM and 3.7 (95\% CI 2.4 to 5.0 ) for patients receiving PDGF/ß- TCP.

\section{Graft collapse}

In all four studies with graft collapse as an outcome measure the use of structural allografts was not associated with a significantly increased graft disintegration or loss of midfoot alignment as compared to structural autologous grafts.

\section{Discussion}

The primary goal of this systematic review was to review the evidence for the efficacy of structural and nonstructural autologous bone grafts and substitutes with respect to rate of union in hindfoot osteotomies and arthrodeses.

We acknowledge several limitations of this study. We pooled data from two different procedures- hindfoot osteotomies and arthrodeses- which may raise concerns from a methodological point of view. However, from a biological standpoint, arthrodeses and osteotomies are very similar situations since in both procedures the bone graft is placed in between fresh bleeding osseous surfaces. We also found major methodological limitations in all studies included in this review. Particularly, small sample sizes and confounding variables were major points of criticism which makes the direct comparison of different grafts types difficult. Therefore, we decided not to report odds ratios, but odds for the rate of union achieved with the individual graft types. In addition, all studies except two $[56,58]$ assessed the presence of bony healing on the basis of plain radiographs which are limited in studying the bony consolidation within the complex anatomy of a fused hindfoot joint or a three dimensional osteotomy [12,59]. The rates of union which were assessed with the use of plain radiography might have been overestimated [12].

The quantitative data analysis performed in this systematic review suggests that structural allografts may be effective substitutes for autologous grafts in these procedures. The pooled random effect odds for union with structural allografts were 12.8 (95\% CI 12.7 to 12.9 ) and thus even higher than those calculated for structural autologous grafts (i.e. 5.7 [95\% CI 5.5 to 6.0]). Nevertheless, the limited quality of the underlying evidence as well as the presence of publication bias may have both inflated the odds for union in the allograft group. However, it is unlikely that more extensive and reliable evidence would change the odds of union for structural allografts to a value which is substantially below that of 
autologous grafts. Therefore, our findings at least suggest an equivalent incorporation of structural allografts as compared to autologous grafts. This conclusion from our quantitative data analysis may further be supported by the fact that the pooled odds for union for cancellous allografts were also very similar to those calculated for cancellous autologous grafts.

One randomized controlled trial [17] and three retrospective chart reviews $[17,52,53]$ also showed no increased risk for graft collapse when allografts were used instead of autologous grafts in Evan's osteotomies, but these data were mainly generated in pediatric studies and thus definitively require further verification in a broad adult patient population.

Furthermore, the individual data from one prospective study [51] and from one small randomized controlled trial [57] indicated that DBM and PDGF augmented ß-TCP ceramic granules could potentially substitute for cancellous autologous grafts in hindfoot fusions. Nonetheless, with the lack of prospective studies with sound methodology, it currently remains unclear if the use of cancellous autologous bone grafts and substitutes is effective in promoting bony healing in arthrodeses of the hindfoot.

To our knowledge, this is the first systematic review on structural and non-structural bone grafts in hindfoot surgery, although many narrative reviews have already been published on this topic [46,60-63]. These narrative reviews mainly focused on the biologic properties of these grafts and did not synthesize results from different studies. On the other hand, there are several systematic reviews and meta-analyses on structural and non-structural autologous bone grafts and substitutes in spine surgery [64-70]. These studies showed conflicting results on the osteointegration of structural allografts. In one meta-analysis [70], structural allografts were associated with a higher frequency of graft collapse and non-union as compared to autologous grafts, but more recent meta-analysis [66] does not confirm these results.

\section{Conclusion}

The current evidence suggests that structural allografts appear to be at least non-inferior to autologous grafts in respect to the odds for union in hindfoot arthrodeses and osteotomies. Considering the large number of bone grafts and substitutes used in hindfoot osteotomies and arthrodeses [71], there is an urgent need for well-designed randomized controlled trials to assess the efficacy of structural and non-structural autologous bone grafts substitutes.

\section{Abbreviations}

DBM: Demineralised bone matrix; Cl: Confidence interval; PDGF: Platelet derived growth factors; TCP: Tricalcium Phosphate.

\section{Competing interest}

The authors declare that they have no competing interests.

\section{Authors' contributions}

The following authors have: designed the study: MAM, MB, AM, W, gathered the data: MAM, AF, AM, analyzed and interpreted the data: $P V, M B, W ; V E$, written the initial draft: MAM, AM, VE, have given final approval of the version published: MAM, W, AM, PV, AF. All authors read and approved the final manuscript.

\section{Acknowledgements}

We wish to thank Professor Rachel Rosenthal, MD for her substantial scientific support in this study.

\section{Author details}

Orthopedic Department University Hospital Basel, Spitalstrasse 21, Basel 4031, Switzerland. ${ }^{2}$ Basel Institute for Clinical Epidemiology and Biostatistics, University Hospital Basel, Hebelstrasse 10, Basel 4031, Switzerland.

${ }^{3}$ Department of Clinical Epidemiology and Biostatistics, McMaster University, 1280 Main Street West, Hamilton, ON L8S 4K1, Canada. ${ }^{4}$ Center for Advanced Orthopedic Studies, Beth Israel Deaconess Medical Center and Harvard Medical School, Brookline Avenue 330, Boston, MA 02215, USA.

Received: 11 June 2012 Accepted: 16 January 2013

Published: 7 February 2013

\section{References}

1. Kelly IP, Easley ME: Treatment of stage 3 adult acquired flatfoot. Foot Ankle Clin 2001, 6:153-166.

2. Kitaoka HB, Patzer GL: Subtalar arthrodesis for posterior tibial tendon dysfunction and pes planus. Clin Orthop Relat Res 1997, 345:187-194.

3. Bolt PM, Coy S, Toolan BC: A comparison of lateral column lengthening and medial translational osteotomy of the calcaneus for the reconstruction of adult acquired flatfoot. Foot Ankle Int 2007, 28:1115-1123.

4. Easley ME, Trnka HJ, Schon LC, Myerson MS: Isolated subtalar arthrodesis. J Bone Joint Surg Am 2000, 82:613-624.

5. Glanzmann MC, Sanhueza-Hernandez R: Arthroscopic subtalar arthrodesis for symptomatic osteoarthritis of the hindfoot: a prospective study of 41 cases. Foot Ankle Int 2007, 28:2-7.

6. Harstall R, Lehmann O, Krause F, Weber M: Supramalleolar lateral closing wedge osteotomy for the treatment of varus ankle arthrosis. Foot Ankle Int 2007, 28:542-548.

7. Myerson M, Quill GE Jr: Late complications of fractures of the calcaneus. J Bone Joint Surg Am 1993, 75:331-341.

8. Chan SC, Alexander IJ: Subtalar arthrodesis with interposition tricortical iliac crest graft for late pain and deformity after calcaneus fracture. Foot Ankle Int 1997, 18:613-615.

9. Mann DC, Hsu JD: Triple arthrodesis in the treatment of fixed cavovarus deformity in adolescent patients with Charcot-Marie-Tooth disease. Foot Ankle 1992, 13:1-6.

10. Santavirta S, Turunen $V$, Ylinen $P$, Konttinen $Y T$, Tallroth $K$ : Foot and ankle fusions in Charcot-Marie-Tooth disease. Arch Orthop Trauma Surg 1993, 112:175-179.

11. Bednarz PA, Beals TC, Manoli A: Subtalar distraction bone block fusion: an assessment of outcome. Foot Ankle Int 1997, 18:785-791.

12. Jones CP, Coughlin MJ, Shurnas PS: Prospective CT scan evaluation of hindfoot nonunions treated with revision surgery and low-intensity ultrasound stimulation. Foot Ankle Int 2006, 27:229-235.

13. Myerson MS, Neufeld SK, Uribe J: Fresh-frozen structural allografts in the foot and ankle. J Bone Joint Surg Am 2005, 87:113-120.

14. Thordarson DB, Kuehn S: Use of demineralized bone matrix in ankle/ hindfoot fusion. Foot Ankle Int 2003, 24:557-560.

15. Chahal J, Stephen DJ, Bulmer B, Daniels T, Kreder HJ: Factors associated with outcome after subtalar arthrodesis. J Orthop Trauma 2006, 20:555-561.

16. Ishikawa SN, Murphy GA, Richardson EG: The effect of cigarette smoking on hindfoot fusions. Foot Ankle Int 2002, 23:996-998.

17. Danko AM, Allen B Jr, Pugh L, Stasikelis P: Early graft failure in lateral column lengthening. J Pediatr Orthop 2004, 24:716-720.

18. Child BJ, Hix J, Catanzariti AR, Mendicino RW, Saltrick K: The effect of hindfoot realignment in triple arthrodesis. J Foot Ankle Surg 2009, 48:285-293

19. Burchardt H: The biology of bone graft repair. Clin Orthop Relat Res 1983, $174: 28-42$.

20. Dell PC, Burchardt H, Glowczewskie FP Jr: A roentgenographic, biomechanical, and histological evaluation of vascularized and non- 
vascularized segmental fibular canine autografts. J Bone Joint Surg Am 1985, 67:105-112.

21. Zerbo $\mathbb{R}$, de Lange $G L$, Joldersma M, Bronckers $A L$, Burger EH: Fate of monocortical bone blocks grafted in the human maxilla: a histological and histomorphometric study. Clin Oral Implants Res 2003, 14:759-766.

22. Einhorn TA, Majeska RJ, Rush EB, Levine PM, Horowitz MC: The expression of cytokine activity by fracture callus. J Bone Miner Res 1995, 10:1272-1281.

23. Albrektsson T, Albrektsson B: Microcirculation in grafted bone. A chamber technique for vital microscopy of rabbit bone transplants. Acta Orthop Scand 1978, 49:1-7.

24. Enneking WF, Burchardt H, Puhl JJ, Piotrowski G: Physical and biological aspects of repair in dog cortical-bone transplants. J Bone Joint Surg Am 1975, 57:237-252

25. DeOrio JK, Farber DC: Morbidity associated with anterior iliac crest bone grafting in foot and ankle surgery. Foot Ankle Int 2005, 26:147-151.

26. Ahlmann E, Patzakis M, Roidis N, Shepherd L, Holtom P: Comparison of anterior and posterior iliac crest bone grafts in terms of harvest-site morbidity and functional outcomes. J Bone Joint Surg Am 2002, 84-A:716-720.

27. Arrington ED, Smith WJ, Chambers HG, Bucknell AL, Davino NA: Complications of iliac crest bone graft harvesting. Clin Orthop Relat Res 1996, 329:300-309.

28. Younger EM, Chapman MW: Morbidity at bone graft donor sites. J Orthop Trauma 1989, 3:192-195.

29. Enneking WF, Campanacci DA: Retrieved human allografts: a clinicopathological study. J Bone Joint Surg Am 2001, 83-A:971-986.

30. Simonds RJ: HIV transmission by organ and tissue transplantation. AIDS 1993, 7(Suppl 2):S35-S38

31. Langer F, Czitrom A, Pritzker KP, Gross AE: The immunogenicity of fresh and frozen allogeneic bone. J Bone Joint Surg Am 1975, 57:216-220.

32. Preston RD, Meinberg TA, Payne JB, Schmid MJ, Lee HM, Golub LM, et al: Inflammatory mediator release following bone grafting in humans: a pilot study. J Clin Periodontol 2007, 34:797-804.

33. Weiland AJ, Phillips TW, Randolph MA: Bone grafts: a radiologic, histologic, and biomechanical model comparing autografts, allografts, and free vascularized bone grafts. Plast Reconstr Surg 1984, 74:368-379.

34. Wilson JW, Rhinelander FW, Stewart CL: Vascularization of cancellous chip bone grafts. Am J Vet Res 1985, 46:1691-1699.

35. Wheeler DL, Enneking WF: Allograft bone decreases in strength in vivo over time. Clin Orthop Relat Res 2005, 435:36-42

36. Nguyen $\mathrm{H}$, Morgan DA, Forwood MR: Sterilization of allograft bone: effects of gamma irradiation on allograft biology and biomechanics. Cell Tissue Bank 2007, 8:93-105.

37. Trentz OA, Hoerstrup SP, Sun LK, Bestmann L, Platz A, Trentz OL: Osteoblasts response to allogenic and xenogenic solvent dehydrated cancellous bone in vitro. Biomaterials 2003, 24:3417-3426.

38. Jahn K, Braunstein V, Furlong PI, Simpson AE, Richards RG, Stoddart MJ: A rapid method for the generation of uniform acellular bone explants: a technical note. J Orthop Surg Res 2010, 5:32.

39. Meyer S, Floerkemeier T, Windhagen $\mathrm{H}$ : Histological osseointegration of Tutobone((R)): first results in human. Arch Orthop Trauma Surg 2007, 128:539-544.

40. Urist MR: Bone: formation by autoinduction. Clin Orthop Relat Res 1965 2002:4-10.

41. Soohoo NF, Cracchiolo A III: The results of utilizing proximal tibial bone graft in reconstructive procedures of the foot and ankle. Foot Ankle Surg 2008, 14:62-66.

42. Wang JC, Alanay A, Mark D, Kanim LE, Campbell PA, Dawson EG, et al: A comparison of commercially available demineralized bone matrix for spinal fusion. Eur Spine J 2007, 16:1233-1240.

43. Schwartz Z, Somers A, Mellonig JT, Carnes DL Jr, Dean DD, Cochran DL, et al: Ability of commercial demineralized freeze-dried bone allograft to induce new bone formation is dependent on donor age but not gender. J Periodontol 1998, 69:470-478.

44. Ohgushi H, Goldberg VM, Caplan Al: Repair of bone defects with marrow cells and porous ceramic. Experiments in rats. Acta Orthop Scand 1989, 60:334-339.

45. Frigg A, Dougall H, Boyd S, Nigg B: Can porous tantalum be used to achieve ankle and subtalar arthrodesis?: a pilot study. Clin Orthop Relat Res 2010, 468:209-216.

46. El-Amin SF, Hogan MV, Allen AA, Hinds J, Laurencin CT: The indications and use of bone morphogenetic proteins in foot, ankle, and tibia surgery. Foot Ankle Clin 2010, 15:543-551.
47. DiGiovanni CW, Petricek JM: The evolution of rhPDGF-BB in musculoskeletal repair and its role in foot and ankle fusion surgery. Foot Ankle Clin 2010, 15:621-640.

48. Stang A: Critical evaluation of the Newcastle-Ottawa scale for the assessment of the quality of nonrandomized studies in meta-analyses. Eur J Epidemiol 2010, 25:603-605.

49. Dersimonian R, Laird N: Meta-analysis in clinical trials. Control Clin Trials 1986, 7:177-188

50. Egger M, Davey SG, Schneider M, Minder C: Bias in meta-analysis detected by a simple, graphical test. BMJ 1997, 315:629-634.

51. Dolan CM, Henning JA, Anderson JG, Bohay DR, Kornmesser MJ, Endres TJ: Randomized prospective study comparing tri-cortical iliac crest autograft to allograft in the lateral column lengthening component for operative correction of adult acquired flatfoot deformity. Foot Ankle Int 2007, 28:8-12.

52. Templin D, Jones K, Weiner DS: The incorporation of allogeneic and autogenous bone graft in healing of lateral column lengthening of the calcaneus. J Foot Ankle Surg 2008, 47:283-287.

53. Kwak YH, Park KB, Park HW, Kim HW: Use of allograft in skeletally immature patients for calcaneal neck lengthening osteotomy. Yonsei Med J 2008, 49:79-83.

54. Grier KM, Walling AK: The use of tricortical autograft versus allograft in lateral column lengthening for adult acquired flatfoot deformity: an analysis of union rates and complications. Foot Ankle Int 2010, 31:760-769.

55. Mahan KT, Hillstrom HJ: Bone grafting in foot and ankle surgery. A review of 300 cases. J Am Podiatr Med Assoc 1998, 88:109-118.

56. DiGiovanni CW, Baumhauer J, Lin SS, Berberian WS, Flemister AS, Enna MJ, et al: Prospective, randomized, multi-center feasibility trial of rhPDGF-BB versus autologous bone graft in a foot and ankle fusion model. Foot Ankle Int 2011, 32:344-354.

57. Michelson JD, Curl LA: Use of demineralized bone matrix in hindfoot arthrodesis. Clin Orthop Relat Res 1996, 325:203-208.

58. McGarvey WC, Braly WG: Bone graft in hindfoot arthrodesis: allograft vs autograft. Orthopedics 1996, 19:389-394.

59. Coughlin MJ, Grimes JS, Traughber PD, Jones CP: Comparison of radiographs and $\mathrm{CT}$ scans in the prospective evaluation of the fusion of hindfoot arthrodesis. Foot Ankle Int 2006, 27:780-787.

60. Cook EA, Cook JJ: Bone graft substitutes and allografts for reconstruction of the foot and ankle. Clin Podiatr Med Surg 2009, 26:589-605.

61. Panchbhavi VK: Synthetic bone grafting in foot and ankle surgery. Foot Ankle Clin 2010, 15:559-576.

62. Rush SM: Bone graft substitutes: osteobiologics. Clin Podiatr Med Surg 2005, 22:30-619. viii.

63. Boone DW: Complications of iliac crest graft and bone grafting alternatives in foot and ankle surgery. Foot Ankle Clin 2003, 8:1-14

64. Agarwal R, Williams K, Umscheid CA, Welch WC: Osteoinductive bone graft substitutes for lumbar fusion: a systematic review. J Neurosurg Spine 2009 11:729-740

65. Lee KJ, Roper JG, Wang JC: Demineralized bone matrix and spinal arthrodesis. Spine J 2005, 5:217S-223S.

66. Miller LE, Block JE: Safety and Effectiveness of Bone Allografts in Anterior Cervical Discectomy and Fusion Surgery. Spine (Phila Pa 1976) 2011, 36:2045

67. Papakostidis C, Kontakis G, Bhandari M, Giannoudis PV: Efficacy of autologous iliac crest bone graft and bone morphogenetic proteins for posterolateral fusion of lumbar spine: a meta-analysis of the results. Spine (Phila Pa 1976) 2008, 33:680-692.

68. Epstein NE: Efficacy of different bone volume expanders for augmenting lumbar fusions. Surg Neurol 2008, 69:16-19.

69. Vaccaro AR, Chiba K, Heller JG, Patel TC, Thalgott JS, Truumees E, et al: Bone grafting alternatives in spinal surgery. Spine J 2002, 2:206-215.

70. Floyd T, Ohnmeiss D: A meta-analysis of autograft versus allograft in anterior cervical fusion. Eur Spine J 2000, 9:398-403.

71. Bostrom MP, Seigerman DA: The clinical use of allografts, demineralized bone matrices, synthetic bone graft substitutes and osteoinductive growth factors: a survey study. HSS J 2005, 1:9-18.

\section{doi:10.1186/1471-2474-14-59}

Cite this article as: Müller et al:: Substitutes of structural and nonstructural autologous bone grafts in hindfoot arthrodeses and osteotomies: a systematic review. BMC Musculoskeletal Disorders 2013 14:59. 